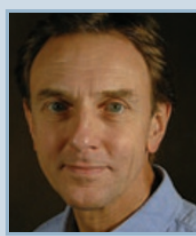

\author{
p1125 Last words: \\ Colin Blakemore \\ ponders the fate \\ of UK medical \\ research.
}

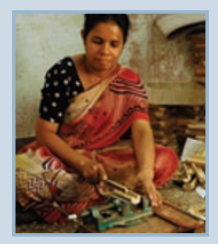

p1128 Sharp focus:
Indian nonprofit
makes cheap
microscopes for
schools.

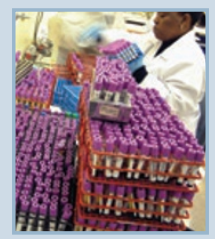

p1131 Life savers:

Simpler tests

for CD4 cells

could help

AIDS clinics.

\title{
Amidst doubts, space research program takes flight
}

Given that all life on earth evolved in the presence of gravity, not all scientists agree that research in space can reveal anything informative. Nonetheless, a few researchers are eager to blast off their cell cultures, hamsters and pathogens into orbit.

On 12 September, the US National Aeronautics and Space Administration (NASA) and the US National Institutes of Health (NIH) launched a joint plan to encourage biomedical research in space.

"The [space] station provides a unique environment where researchers can explore fundamental questions about human health issues - including how the body heals itself, fights infection or develops diseases such as cancer or osteoporosis," NIH director Elias Zerhouni said at the announcement on Capitol Hill.

But closer examination reveals that the project does not come with any new money to fund research. NASA is offering up room for experiments on the International Space Station, a 14,000-cubic-foot facility that orbits 220 miles above the earth and is shared by Russia, Japan, Canada, Brazil, the US and Europe. The expense of NIH projects in the station, including the high costs of getting equipment and materials there, will have to be paid by the NIH.

NASA's own funding for basic research nearly

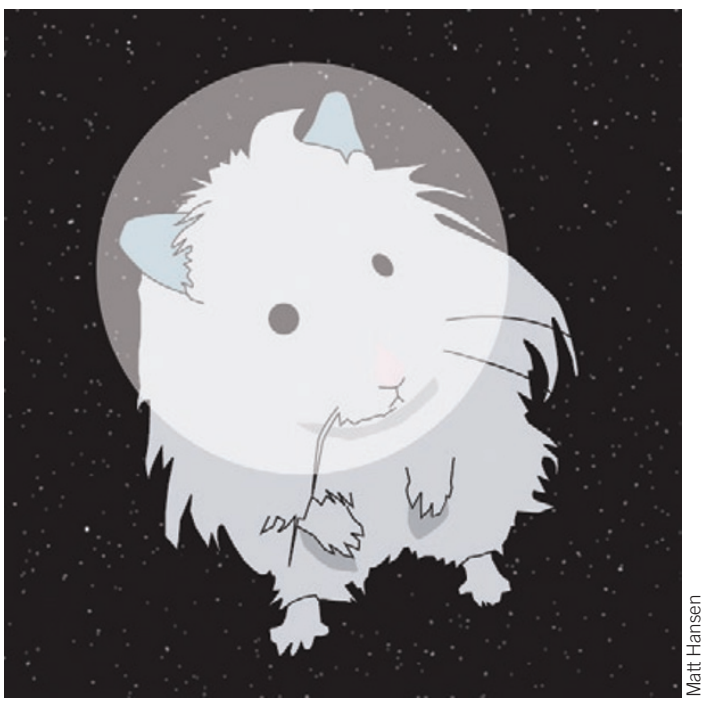

Empty promises? There's no new money to fund biomedical research in space. dried up three years ago, when President Bush called for a new focus on expeditions to the moon and to Mars. After the shuttle Columbia blew up in 2003, NASA also cut back the number of planned flights to the space station and cancelled several pieces of scientific equipment intended for the station, including a large centrifuge module planned by Japan. As a result, the agency is leaving unused some 22 cubic-meter racks set aside for science experiments.

Because there is no new money in the deal, the agreement might not lead to much new research, notes Keith Cowling, a former space station program manager and gadfly blogger.

"It is somewhat hollow given the current state of the space station," Cowling says. "The space station has profound potential that has not been tapped and may not be tapped."

In the mid-1980s, when NASA was trying to convince the US Congress to fund a space station, the agency estimated that it would cost $\$ 8$ billion and be complete by 1994 . Two shuttle disasters and more than $\$ 25$ billion dollars later, the new date for completion is 2010.

The European Space Agency and the Japanese Aerospace Exploration Agency have built their own research modules for the space station, both of which are waiting to be flown up and attached. In the meantime, the European agency on 14 September launched the Foton microgravity mission, which is carrying, among other things, 26 baby cichlid fish that will have their innerear development monitored as they grow in microgravity.

"It may well be that the US paid the lion's share of the construction of the [international space station] and got the smallest amount of direct science return," says Cowling. "That's a shame."

NASA's research funding is focused almost completely on studying the deleterious effects of spaceflight on people. The problems are not trivial: serious bone density loss, ionizing radiation and even the psychological strain of prolonged isolation plague astronauts.

"The station is our space biomedical r e s e a r ch laboratory," says Steve

Davison, program executive in NASA's Advanced Capabilities Division. "It is critical for us to assess human health space risks."

There are also a few experiments underway in more basic biology. For example, Salmonella typhimurium, which causes foodborne illnesses, is more virulent in space than it is on earth. And cells grown in a liquid culture in microgravity do not huddle against the plastic, but float in a bath of low fluid shear forces, not unlike that found in certain compartments in the body, such as the villi of the respiratory tract.

Although many people, including scientists, question the advantages of research in space, "We know that a lot of our knowledge has been gained from testing biological systems at their extremes- $\mathrm{pH}$, temperature and so on," says Cheryl Nickerson, a biologist at Arizona State University in Tempe, who works on the Salmonella project. "Every time we do this, we find out something new about how systems and cells do the things [they] do. We are looking at pushing a system to another extreme now."

Playing with those extremes will be an expensive endeavor, however. Because the aging fleet of space shuttles is scheduled to be retired at about the same time as the space station is complete and ready for experiments, the experimental racks will have to catch a ride either with the Russian space shuttle, with as-yet unbuilt systems from Europe or Japan, or with NASA's planned Orion crew vehicle, which the agency hopes to launch in 2014.

According to Mark Uhran, assistant associate administrator for the station, the preferred vehicles are likely to be space transportation services run by private companies. "The space station has been in the construction phase so we have not initiated the research program in earnest and will not until it is complete," says Uhran. "We think the timing is just about right three years in advance to get people thinking about this."

Emma Marris, Columbia, Missouri 